\title{
Spatial Distribution Characteristics of Oil Spills in the Bohai Sea Based on Satellite Remote Sensing and GIS
}

\author{
Lei Bing ${ }^{\dagger, \dagger}$, Qian-Guo Xing ${ }^{\dagger, \dagger^{*}}$, Xin Liu ${ }^{\dagger,},{ }^{\dagger}$, and Na-Na Zou ${ }^{\S}$
}

CAS Key Laboratory of Coastal Environmental Processes and Ecological Remediation

Yantai Institute of Coastal Zone Research (YIC)

Shandong Key Laboratory of Coastal Environmental

Processes YICCAS

Yantai, China

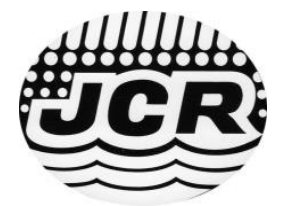

www.JCRonline.org

\author{
${ }^{\dagger}$ University of Chinese \\ Academy of Sciences \\ Beijing, China
}

\author{
${ }^{\S}$ School of Mathematics \\ and Statistics \\ Central South University \\ Changsha, China
}

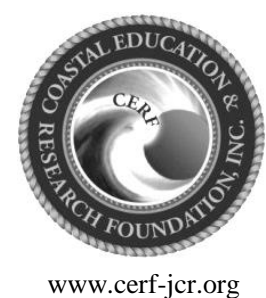

www.cerf-jcr.org

\begin{abstract}
Bing, L.; Xing, Q.-G.; Liu, X., and Zou, N.-N., 2019. Spatial distribution characteristics of oil spills in the Bohai Sea based on satellite remote sensing and GIS. In: Jung, H.-S.; Lee, S.; Ryu, J.-H., and Cui, T. (eds.), Advances in Remote Sensing and Geoscience Information Systems of Coastal Environments. Journal of Coastal Research, Special Issue No. 90, pp. 164-170. Coconut Creek (Florida), ISSN 0749-0208.

In recent years, on account of the vast and persistent damage of oil spill accidents, it becomes essential to carry out a further study on oil spill distribution characteristics on sea. Routine satellite remote sensing surveillance on oil spills with Synthetic Aperture Radar (SAR) proved to be ideal for analyzing distribution of oil pollution in macro scale. In this research work, considering the presence of "look-alikes" phenomena on SAR images as well as current operational application of "confidence level", a confidence-oriented oil spill geodatabase is initially designed and built for quantification analysis. Then, in view of the requirement of marine grid management, a common framework based on remote sensing and Geographic Information System (GIS) is proposed to map and reveal the spatial distribution of oil pollution, in the process of which, oil pollution index (OPI) is put forward to evaluate oil pollution levels, then oil pollution distribution map can be compiled in terms of OPI, and the relationship between oil pollution and oil spill risk source can be further analyzed. Finally, a case study of the Bohai Sea and the north of the Yellow Sea with five-year's inter-annual satellite monitoring data was studied. The results showed that, during the period between 2009 and 2013, the high frequency grids of potential oil spills mainly distributed in the Bohai Bay and the south of the Liaodong Bay. $77.03 \%$ of detected oil spills were within a certain distance along the sea lanes or near the offshore platforms, indicating a high risk of oil pollution of these areas. Generally, this research work also benefits for yield for the first time a rather comprehensive distribution characteristics of potential oil spills in macro scale in the Bohai Sea combined with remote sensing and GIS technique, which will be beneficial for oil spill response, preparedness and risk management.
\end{abstract}

ADDITIONAL INDEX WORDS: Oil spill, oil pollution index (OPI), satellite remote sensing, spatial distribution characteristics, the Bohai Sea.

\section{INTRODUCTION}

Oil spill is considered as one of major threats to marine ecosystem. Since the early 1970s, International Maritime Organization (IMO) has been working to prevent this kind of pollution in the framework of MARPOL73/78, which in Annex1 deals specifically with prevention of oil pollution (Martínez and Moreno, 1996). In recent years, huge oil spills still occurred irregularly, such as Deepwater Horizon (DWH) spill in the Gulf of Mexico, the Dalian 7.16 oil pollution accident in China, Both the public and the local government have a focus on oil spill risk analysis and preparedness. Meanwhile, it becomes essential to carry out further study on the characteristics and laws of oil pollution at sea, which will directly benefit for oil pollution emergency preparedness.

Satellite remote sensing has been extensively used to detect oil spills on sea surface (Brekke and Solberg, 2005; Fingas and Brown, 1997; Keydel and Alpers, 1987; Xing et al., 2015;

DOI: 10.2112/SI90-020.1 received 25 January 2019; accepted in revision 16 April 2019.

*Corresponding author: qgxing@yic.ac.cn

${ }^{\circ}$ Coastal Education and Research Foundation, Inc. 2019
Zhang et al., 2016). Passive optical remote sensing of oil spills using sunlight has been used for several decades, and significant progress in oil spill detection, classification, and quantification based on different optical properties and algorithms have been made in recent years (Lu et al., 2016; Su et al., 2012). Laser induced fluorescence technique has also been used for the detection of marine oil spills (Luan et al., 2017). During the vast and persistent BP deepwater horizon oil spill accident in 2012, extensive airborne and spaceborne passive and active remote sensing were used to monitor oil spills and provide rapid response (Leifer et al., 2012). In practical application, oil spill can be detected more effectively by Synthetic Aperture Radar (SAR) images because it damps short surface waves and thus reduces the backscattered radar power over these areas. As a result, SAR is more widely used for oil spill monitoring in application. A detailed state-of-the-art for oil spill detection methodology using SAR imagery is discussed by a number of scientists including Ferraro et al. (2012), Liu et al. (2011), Martínez and Moreno (1996), Solberg et al. (2007), and Topouzelis et al. (2007). It is very valuable for decision-makers to understand the characteristics of oil spills, which will directly benefit for oil spill emergency preparedness. Garcia et al. (2013) 
developed an Oil Spill Hazard Index (OSHI) to evaluate the pollution risk level along the whole Italian coastline and waters. Liu et al. (2015) utilized satellite images together with historic accident data to establish probability of oil spills to assess oil spill risks. Yu et al. (2018) showed that oil spill risk assessment in the Chinese Bohai Sea becomes more important for efficient prevention. Some successful experiments and projects have been carried out to monitor oil spills via space-borne SAR images and study its distribution characteristics through big data. For instance, Pavlakis, Tarchi, and Sieber (1996) interpreted 190 ERS-1 SAR images to analyze oil spill distribution in the Mediterranean. More than 660 ERS-2 SAR images covering the southern Baltic Sea, the North Sea, and the Gulf of Lion were analyzed within the "Clean Seas" project, which was funded by the European Community (EC), aiming at investigating the application of remote sensing for oil spill detection and coastal management (Gade et al., 1998). With the rapid development of Geographic Information System (GIS), it provided a useful tool for mapping and spatial analysis at large scales (Choi et al., 2011; Zinck et al., 2001). In order to get enough knowledge on spatial distribution characteristics of oil pollution on sea, oil slick information extracted from SAR images can be used to make zoning maps for oil pollution. A GIS approach to mapping marine oil pollution was applied to the Sea of Okhotsk, the Caspian Sea, the Black Sea and the Gulf of Thailand, respectively (Ivanov and Zatyagalova, 2008). In China, based on over six thousands of ERS-1/2 SAR images acquired within the period from 1995 to 1998 , Lu et al. (1999) mapped the spatial distribution of oil pollution in the Southeast Asian waters. In 2008, Shi et al. (2008) interpreted more than 600 SAR images captured from 2002 to 2005 in the western part of the East China Sea, then analyzed and mapped the spatial distribution of oil spills.

However, owing to the complexity of space-borne SAR imaging mechanism and ocean-atmosphere system, there are also a large number of "look-alikes" phenomena which can easily be mistaken as oil slicks on SAR images. e.g., some areas with low wind speed or upwelling areas can also generate dark patches, that is, oil spill detection on SAR images highly depends on individual experience to a certain extent. As a result, different labels of "confidence", such as high level, medium level or low level, are commonly used to describe the uncertainty of interpretation results in operational application (Ferraro et al., 2010). Unfortunately, this uncertainty rarely reflected in an oil pollution distribution maps. At the same time,

China Maritime Safety Administration (MSA) are implementing maritime grid management in territorial waters, in which how to combine the uncertainty of oil slick detection on SAR images, spatial analysis of GIS and the requirement of maritime grid management in one oil pollution zoning map becomes an important issue.

Table 1. Statistics of original SAR images.

\begin{tabular}{ccccccc}
\hline \hline Data sources & 2009 & 2010 & 2011 & 2012 & 2013 & total \\
\hline Envisat-1 & 29 & 24 & 0 & 8 & 0 & 61 \\
Radarsat-1/2 & 22 & 18 & 29 & 82 & 111 & 262 \\
Total of SAR images & 51 & 42 & 29 & 90 & 111 & 323 \\
\hline
\end{tabular}

In this research work, a confidence-oriented oil spill geodatabase storing information both extracted from SAR images and acquired from on-site investigation was designed and built initially for quantification analysis. Then, an estimation methodology for oil pollution based on confidence-oriented oil spill geodatabase and GIS was proposed, in which the oil pollution index (OPI) was proposed and calculated. Finally, a case study was carried out based on a five-year routine satellite monitoring of oil pollution in the Bohai Sea and the north of the Yellow Sea, then oil pollution maps were compiled in terms of OPI and meanwhile the spatial distribution of oil pollution was discussed in macro scale for the purpose of providing some valuable information for oil spill risk management.

\section{Study Area}

\section{METHODS}

The study area is located between $117^{\circ} \mathrm{E}$ and $123^{\circ} \mathrm{E}$, and $37^{\circ} \mathrm{N}$ and $41^{\circ} \mathrm{N}$. It includes the Bohai Sea and the northern part of the Yellow Sea (Figure 1). In particular, as China's continental sea, the Bohai Sea plays a significant role in national economy and social development. There are three bays from north to south, including the Liaodong Bay, the Bohai Bay, and the Laizhou Bay, and also several main ports, such as the ports of Yingkou, Qinhuangdao, Tianjin, Dalian, Yantai, etc. With the increasing number of shipping business and offshore oil exploitation, the risk of oil pollution in this region is getting higher and higher. Specifically, in recent years, according to the data from Vessel Traffic Control (VTS) it showed that the number of the actual accidents in relation to the intense maritime traffic that taken place in this area increased gradually. Besides, as one of the most important areas where petroleum enriched and produced, some major oilfields, such as Jinzhou oilfield, Bozhong oilfield, Chengbei oilfield, Penglai oilfield, etc., were located in the Bohai Sea. All of these factors lead to a high risk of oil pollution in this study area.

\section{Data Acquisition}

The Bohai Sea was chosen for the study also due to the availability of the necessary oil spill remote sensing data. During the period from January 2009 to December 2013, the China Maritime Safety Administration carried out satellite remote sensing surveillance for oil spills in the Bohai Sea and the north of the Yellow sea, acquiring copious number of oil pollution information both accidental spills and non-reported oil spills. A total of 323 SAR images were collected for oil spill monitoring, including Envisat-1 and Radarsat-1/2 (Table 1 and Table 2).

Table 2. Statistics and comparisons of potential oil spills detected from SAR images.

\begin{tabular}{ccccccc}
\hline \hline Number & 2009 & 2010 & 2011 & 2012 & 2013 & total \\
\hline $\begin{array}{c}\text { Potential } \\
\text { oil spills }\end{array}$ & 43 & 51 & 33 & 26 & 56 & 209 \\
$\begin{array}{c}\text { Images } \\
\text { covering } \\
\text { oil spills }\end{array}$ & 11 & 10 & 11 & 14 & 20 & 66 \\
$\begin{array}{c}\text { Original } \\
\text { SAR } \\
\text { images }\end{array}$ & 51 & 42 & 29 & 90 & 111 & 323 \\
$\begin{array}{c}\text { Occurrence } \\
\text { rate }\end{array}$ & $21.6 \%$ & $23.8 \%$ & $37.9 \%$ & $15.6 \%$ & $18.0 \%$ & $20.4 \%$ \\
\hline
\end{tabular}




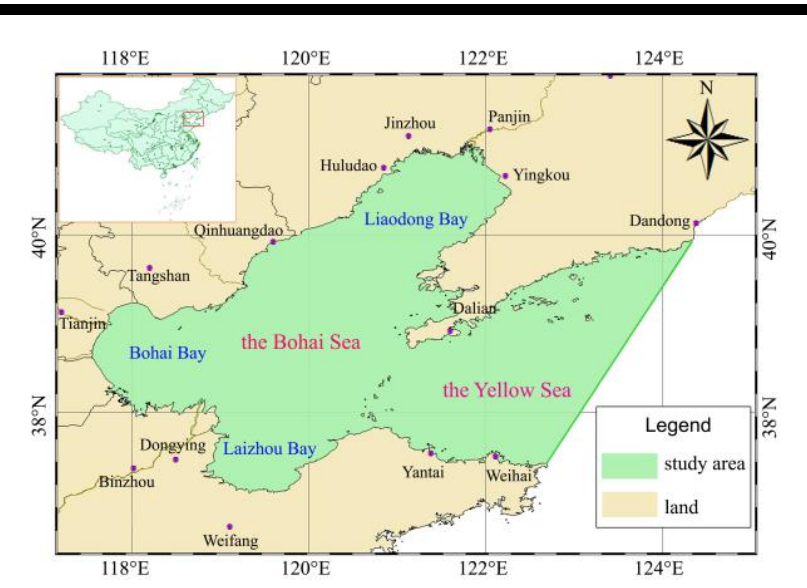

Figure 1. Geographic location of the Bohai Sea and the north of the Yellow Sea. The study area is annotated by green background.

The spatial resolution of these data was from $8 \mathrm{~m}$ to $30 \mathrm{~m}$, mainly by VV polarization. In addition, auxiliary data, such as wind velocity, electronic nautical chart, AIS marine traffic data, offshore platform data, etc., were also used for aid analysis and oil spill detection. The software PCI 10.3 was used for image processing, and ArcGIS 10.0 and Matlab for data analysis.

sensing surveillance for oil spills in the Bohai Sea and the north of the Yellow sea, acquiring copious number of oil pollution information both accidental spills and non-reported oil spills. A total of 323 SAR images were collected for oil spill monitoring, including Envisat-1 and Radarsat-1/2 (Table 1 and Table 2). The spatial resolution of these data was from $8 \mathrm{~m}$ to $30 \mathrm{~m}$, mainly by VV polarization. In addition, auxiliary data, such as wind velocity, electronic nautical chart, AIS marine traffic data, offshore platform data, etc., were also used for aid analysis and oil spill detection. The software PCI 10.3 was used for image processing, and ArcGIS 10.0 and Matlab for data analysis.

\section{Methodology}

Three steps were conducted in this study: (a) building a confidence-oriented oil spill geodatabase; (b) creating a net grid covering the study area, establishing and calculating oil pollution index (OPI) for each grid cell to evaluate oil pollution level; (c) generating oil spill distribution map base on OPI and analyzing spatial characteristic with GIS, as described below.

\section{Confidence-oriented Oil Spill Geodatabase}

As mentioned above, different labels of "confidence" are commonly used to describe to what extent a potential oil slick detected from SAR images to be a real one. But descriptions such as high level, medium level or low level are not suited for quantitative calculation. So, "confidence index" is designed to transfer qualitative evaluation to quantitative calculation.

As is shown in Table 3, confidence index with the numerical value ranging from 0 to 1 is defined to measure the probability of a potential oil slick on SAR images to be a real one. For example, if the confidence index of a potential oil slick is 0.9 , it indicates that the probability of this potential oil slick to be a real one is very high, almost between $80 \%$ to $100 \%$, and it will be classified as category II. Confidence index of each potential oil slick can be determined by two steps:

a) Calculating preliminary confidence index using the Analytic Hierarchy Process (AHP) and the expert scoring method (Dey, Ogunlana, and Naksuksakul, 2004). That is, in this process, each potential oil slick on SAR images will be interpreted by at least 7 experts and marked independently in the light of the probability of being a real one. Then AHP is applied to determine the preliminary confidence index.

b) Determining final confidence index based on on-site verification. In general, if conditions permit, patrol ships or aircrafts will be sent to check the potential oil slick as soon as it is interpreted from SAR images, then the final confidence index will be corrected according to the results of on-site investigations. For instance, if the preliminary confidence index of a potential oil slick is calculated to be 0.9 in the first step, after on-site verification in the second step, it is confirmed as a real oil slick, the final confidence index will therefore be revised to 1 (Figure 2). Of course, not every oil slick detected from remote sensing images can be checked by on-site verification. In this case, the final confidence index will be in accordance with the preliminary confidence index.

With the item of "confidence index", a confidence-oriented oil pollution geodatabase is therefore built, some other information is also stored and managed in this database, including geographic position of oil slicks, vector shape, lengths and area of oil slicks, acquiring date and time of SAR images, etc. Each oil slick item is supposed to be stored as a single vector layer.

\section{Oil Pollution Index (OPI)}

In this section, a regular net grid covering the study area will be firstly established in accordance with both the needs of marine grid management and the basic state of oil spills in this region. The whole study area is therefore divided into 5263 grids with the scale of $5 \times 5 \mathrm{~km}$.

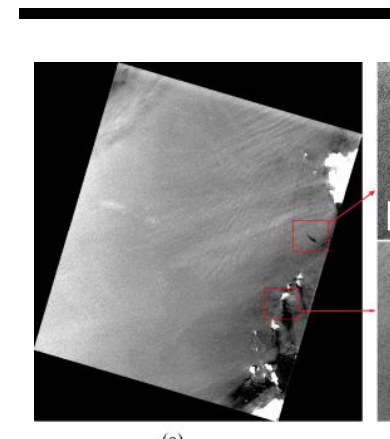

(a)

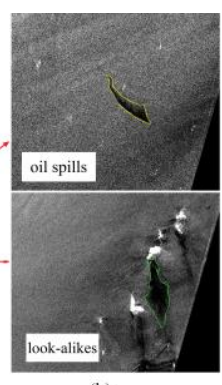

(b)

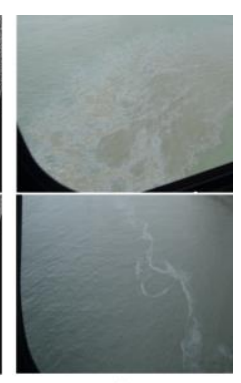

(c)
Figure 2. Examples of determining confidence index of potential oil slicks on SAR images: (a) Radarsat-2 image; (b) oil spills and lookalikes detected from the image; the confidence index of the top right potential oil slick is 1 (marked with yellow line), the confidence index of the bottom right potential oil slick is 0 (marked with green line); (c) optical photos of oil spills validated by aerial remote sensing monitoring (helicopter). 
Table 3. Classification of oil pollution confidence index.

\begin{tabular}{cccc}
\hline \hline category & Probability for oil pollution & confidence index & Description \\
\hline I & $100 \%$ & 1 & Oil slicks checked by facts \\
II & $80 \% \leq \mathrm{p}<100 \%$ & 0.9 & Very high confidence level \\
III & $60 \% \leq \mathrm{p}<80 \%$ & 0.7 & High confidence level \\
IV & $40 \% \leq \mathrm{p}<60 \%$ & 0.5 & Medium confidence level \\
V & $20 \% \leq \mathrm{p}<40 \%$ & 0.3 & Low confidence level \\
VI & $0 \%<\mathrm{p}<20 \%$ & 0.1 & Very low confidence level \\
VII & $0 \%$ & 0 & Look-alikes \\
\hline
\end{tabular}

Then, in order to evaluate oil pollution levels at sea, oil pollution index (OPI) is proposed on the basis of oil spill frequency and corresponding confidence index. The OPI for each grid cell will be calculated following the two steps: a) calculating grid value of oil spill frequency for every layer; b) calculating OPI for each grid.

a) grid value of oil spill frequency for each layer

Generally, frequency is an universal indicator used to evaluate the probability of a random event. In this paper, oil spill frequency is selected as the key indicator to represent the risk of potential oil pollution. Eq. (1) is used to calculate grid value of oil spill frequency for each layer. In this step, each potential oil spill layer is overlaid with the $5 \times 5 \mathrm{~km}$ regular grids, and a new layer with the same extent as the study area is then generated by the logic overlay operation:

$$
\mathrm{f}_{(\mathrm{i}, \mathrm{j}, \mathrm{k})}=\left\{\begin{array}{l}
0, \mathrm{~L}_{\mathrm{k}} \cap \mathrm{G}_{(\mathrm{i}, \mathrm{j})}=\varnothing \\
1, \mathrm{~L}_{\mathrm{k}} \cap \mathrm{G}_{(\mathrm{i}, \mathrm{j})} \neq \varnothing
\end{array}\right.
$$

where

$\mathrm{L}_{\mathrm{k}}$ is the potential oil spill layer $\mathrm{k}, \mathrm{k}$ is the sequence number of oil spills ,and it ranges from 1 to 209; and

$\mathrm{G}_{(\mathrm{i}, \mathrm{j})}$ is the $5 \times 5 \mathrm{~km}$ regular grids raster layer of the study area, it is a logical value to indicate whether an oil spill was located in grids; and

$f_{(i, j, k)}$ is a new generated layer with the same extent as the study area.

When the intersection of two layers is non-empty, the attribute value of the corresponding grid cell of the new generated raster layer is assigned to be 1 , otherwise to be 0 .

b) oil pollution index (OPI) for each grid.

The second step is to calculate oil pollution index (OPI) for each grid using Eq.(2).

$$
\mathrm{OPI}_{(\mathrm{i}, \mathrm{j})}=\sum_{\mathrm{k}} \mathrm{f}_{(\mathrm{i}, \mathrm{j}, \mathrm{k})} \cdot \mathrm{C}_{\mathrm{k}}
$$

where

$\mathrm{C}_{\mathrm{k}}$ is the confidence index of potential oil slicks of layer $\mathrm{k}$; and

$\mathrm{OPI}_{(\mathrm{i}, \mathrm{j})}$ is the oil pollution index of grid cell $(\mathrm{i}, \mathrm{j})$.

$\mathrm{OPI}_{(i, j)}$ is a measurable indicator representing pollution level of a grid cell potentially polluted by oil spills. It is concerned with oil spill frequency of the grid and the confidence index of oil slicks in the grid.

Normalizing $\mathrm{OPI}_{(\mathrm{i}, \mathrm{j})}$ gives

$$
P_{(i, j)}=\frac{O P I_{(i, j)}}{N_{(i, j)}} / \max \left(\frac{O_{(P I}(i, j)}{N_{(i, j)}}\right)
$$

where

$P_{(i, j)}$ is the relative measure of oil pollution index in grid cell $(i, j)$.

$N_{(i, j)}$ is the total number of images counted on grid cell $(i, j)$.

The result of $\mathrm{P}_{(\mathrm{i}, \mathrm{j})}$ is a score between 0 and 1 for per grid cell, the higher the value of the score, the more possible the grid area is affected by oil spills. The $\mathrm{P}_{(\mathrm{i}, \mathrm{j})}$ parameter is not absolute but relative, the outcome can be used to compare both the relative probability of the whole waters and the level of oil spill risk in different grid areas. An oil pollution map can be produced on the basis of the calculation of $\mathrm{OPI}_{(\mathrm{i}, \mathrm{j})}$ or $\mathrm{P}_{(\mathrm{i}, \mathrm{j})}$.

\section{Statistical Analysis}

\section{RESULTS}

In the case study, as mentioned above, the results presented here concern mainly on non-reported oil spills detected from routine satellite remote sensing of the Bohai Sea and the north of the Yellow Sea. A total of 323 SAR images over 5 years since 2009 are used to investigate oil spill distribution, the majority of which is from Radarsat-1/2 and Envisat-1. After interpreting these images, 209 potential oil slicks have been detected from 66 images (sometimes more than one oil slicks in an individual SAR image), accounting for $20.43 \%$ of the total 323images studied, that is to say, oil slicks can be found in one image out of five during the period between 2009 and 2013(see Figures 3a, $3 b$ ). In addition to the number of oil spills, another important factor to reflect the risk level of oil pollution is the area size of oil slicks which can be extracted from SAR images as well. As it appears in Figure 3c, the total area of these spills is $834.63 \mathrm{~km}^{2}$, and the tendency of annual area of detected spills is on the whole increasing dramatically, indicating a sharp growth of oil spill risk during the study period. The area sizes of oil spills varied from $0.01 \mathrm{~km}^{2}$ to even more than $48 \mathrm{~km}^{2}$, about $42.58 \%$ of the spills are less than $1 \mathrm{~km}^{2}$, the number of spills between area size of 1 to $10 \mathrm{~km}^{2}$ is $45.93 \%$. This means the majority (almost $88.52 \%$ ) of the total spills during the study period are less than $10 \mathrm{~km}^{2}$. Monthly statistics of the whole 5 years shows that the monthly variation of average area of oil slicks is not obvious (see Figure 3d).

\section{Spatial Distribution Analysis}

Spatial distribution is able to provide useful information to the authority for oil spill preparedness, for instance, based on the map compiled on the basis of OPI, the administrator can make up targeted routine cruise plans along areas with high oil pollution levels. In addition, emergency resources can be deployed as near these areas as possible for oil spill response. 
The spatial distribution map of potential oil spills in terms of OPI was shown in Figure 4, all the grids were divided into 4 categories by means of Natural Breaks (Michael John De Smith and Paul, 2009), obviously the frequency of oil spill was relatively high in the Bohai Bay, the south of the Liaodong Bay, the middle of the Bohai Sea, and the northwest of the Yellow Sea. The total number of grid cells with oil pollution index higher than or equals to $2\left(\mathrm{OPI}_{(\mathrm{i}, \mathrm{j})} \geq 2\right)$ was 113 .
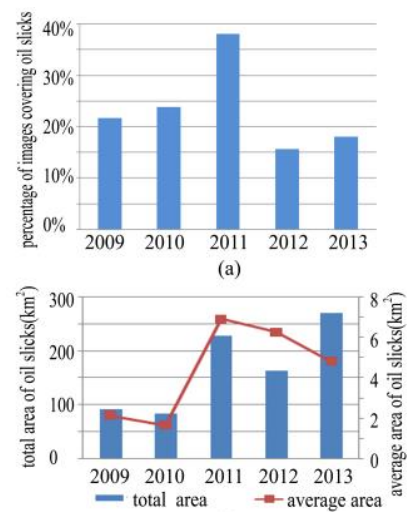

(c)

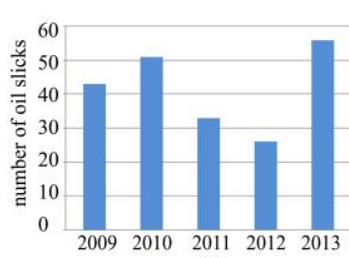

(b)

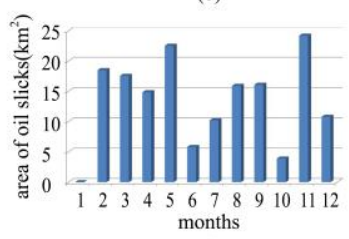

(d)
Figure 3. Histogram of statistics of potential oil slicks from January 2009 to December 2013: (a) proportion of SAR images covering potential oil slicks; (b) annual number of potential oil slicks detected from SAR images; (c) total/average area of potential oil slicks each year and (d) monthly statistics of potential oil slicks area of 5 years.

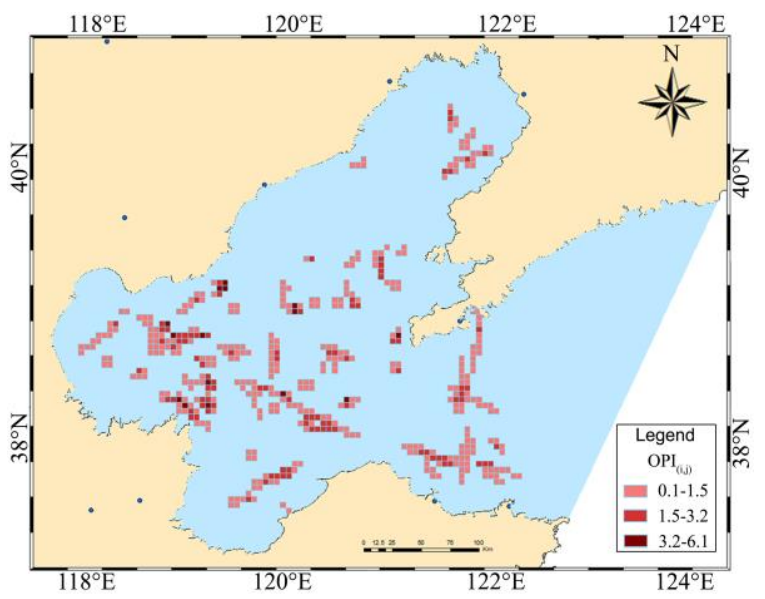

Figure 4. Spatial distribution map of potential oil spills based on OPI in the Bohai Sea and north of the Yellow Sea during the period of January 2009 to December 2013.

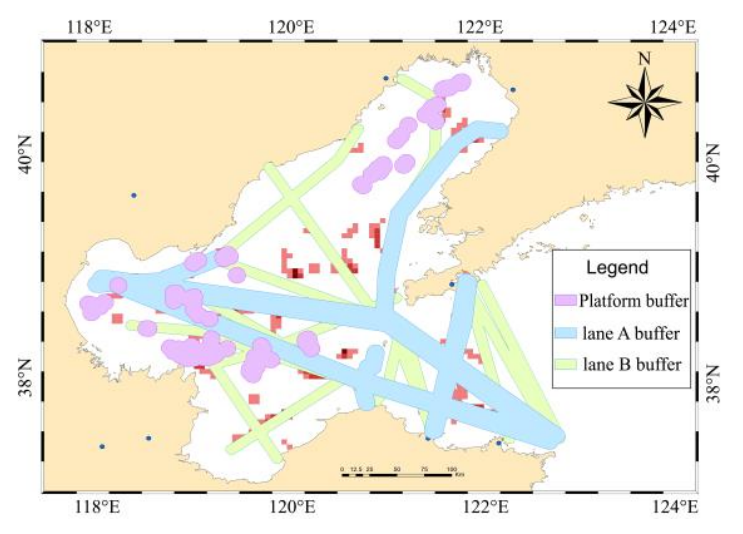

Figure 5. Buffer analysis of main sea routes and offshore platforms of the study waters.

The result of oil spill spatial distribution basically agreed with a recent research that investigated regional and seasonal features of potential oil slick with satellite SAR images covering the Bohai Sea in 2011 (Ding et al., 2016). However there were some differences in oil spill temporal distribution. It was probably due to various SAR data types and different time scales of selected study samples. As the non-uniform spatial repetition density of the routine satellite SAR images of the whole study area, the results are then somehow biased towards these data.

In order to investigate the relationship between oil spills detected from SAR images and the major oil spill hazards in the waters, a further buffer analysis was carried out using GIS tools. The main sea lanes and offshore platforms of the waters are selected as oil spill hazards.

As presented in Figure 5, the main sea lanes were divided into two types (lane A and lane B) according to vessel traffic density. Based on a series of experiments, the buffer distance of offshore platforms and lane A was selected as $8 \mathrm{~km}$, and that of lane B was $5 \mathrm{~km}$, so that the characteristics and relationship could be reflected better and more clearly. The results were presented in Figure 6, the number of spills within the buffer distance to the two types of sea lanes was 116, representing $55.5 \%$ of all detected spills, these results were well in accordance to the study which concluded that most oil slick originate from ships (Ding et al., 2016). A connection between oil spills and ship lanes was Southeast Asian waters (Lu et al., 1999), the Mediterranean sea also obtained from some other waters in the world, like the (Pavlakis, Tarchi, and Sieber, 2001), the Azov and Black Seas (Bedritskii et al., 2007) and the East China Sea (Shi et al., 2008). In particular, the proportion of those to platforms was about $21.53 \%$, which indicated that platform was also a major hazard causing potential oil spills in the Bohai Sea. What's more, the number of spills with the distance equaled zero was 50 , that is to say, about $23.92 \%$ were more likely to be caused by the corresponding hazards. The average distance was $655.84 \mathrm{~m}$, $732.03 \mathrm{~m}$, and $1481.13 \mathrm{~m}$ between oil slicks detected and offshore platforms, lane $\mathrm{A}$, lane $\mathrm{B}$, respectively. 


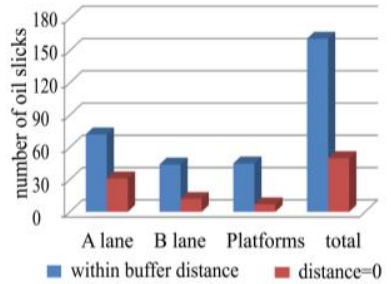

(a)

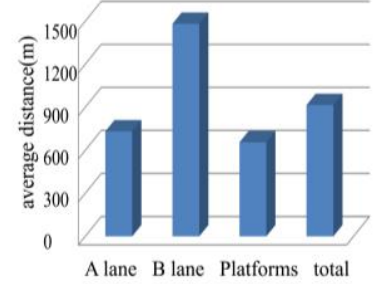

(b)
Figure 6. Buffer analysis of oil spills detected and the major oil spill haz ards in the study waters: (a) number of oil slicks within certain buffer dis tance and that of distance $=0$ and (b) the average distances between oil sli cks detected and the hazards.

\section{CONCLUSIONS}

In this research, considering the presence of "look-alikes" phenomena on SAR images, which leads to the problem of uncertainty for potential oil spills in operational application, a confidence-oriented oil spill geodatabase was designed and built for quantification analysis. Then, an estimation methodology for oil pollution based on satellite remote sensing and GIS was proposed. During this process, the oil pollution index (OPI) was put forward and calculated. In the end, oil pollution map was compiled in terms of OPI and the spatial distribution of oil pollution was discussed.

Generally speaking, the results of the case study in the Bohai Sea and the North of the Yellow Sea showed that, during the period of 2009 to 2013, the high frequency grids of potential oil spills mainly distributed in the Bohai Bay, the south of the Liaodong Bay, the middle of the Bohai Sea, and the northwest of the Yellow Sea. $77.03 \%$ of detected oil spills were within a certain distance along the sea lanes or near the offshore platforms, indicating a high risk of oil pollution of these areas. With this information at hand, the government can give priority to these areas and seasons being prone to oil pollution when drawing up routine marine cruise and air cruise plans.

Although this research work is preliminary in the Bohai Sea, it yields for the first time a rather comprehensive spatial distribution map of potential oil spills combined with remote sensing and GIS technique, which will to some extent be beneficial for oil spill risk preparedness and management. However, for such random events as oil spills, a great deal of long-term surveillance data with SAR images is highly recommended to study the characteristics and laws of oil pollution, since the results might be improved by data mining on large amounts of statistical data better and more objectively.

\section{AUTHOR CONTRIBUTIONS}

All of these authors contributed equally to this work.

\section{ACKNOWLEDGEMENT}

This work was supported by Chinese Academy of Sciences (Nos. XDA19060501,YJKYYQ20170048), the National Natural Science Foundation of China (Nos. 41676171, 61890964), the
Qingdao National Laboratory for Marine Science and Technology of China (No. 2016ASKJ02), and Routine Satellite Remote Sensing Monitoring Project in the Bohai Sea and North of the Yellow Sea by Yantai Maritime Safety Administration. We are also grateful to reviewers whose suggestions have significantly contributed to improving the quality of the manuscript.

\section{LITERATURE CITED}

Bedritskii, A.I.; Asmus, V.V.; Krovotyntsev, V.A.; Lavrova, O.Y., and Ostrovskii, A.G., 2007. Satellite monitoring of pollution in the Russian sector of the Azov and Black Seas in 2003-2007. Russian Meteorology and Hydrology, 32(11), 669-674.

Brekke, C. and Solberg, A.H.S., 2005. Oil spill detection by satellite remote sensing. Remote Sensing of Environment, 95(1), 1-13.

Choi, J.-K.; Oh, H.-J.; Koo, B.J.; Lee, S., and Ryu, J.-H., 2011. Macrobenthos habitat mapping in a tidal flat using remotely sensed data and a GIS-based probabilistic model. Marine Pollution Bulletin, 62(3), 564-572.

Dey, P.K.; Ogunlana, S.O., and Naksuksakul, S., 2004. Riskbased maintenance model for offshore oil and gas pipelines: a case study. Journal of Quality in Maintenance Engineering, 10(3), 169-183.

Ding, Y.; Cao, C.; Huang, J.; Song, Y.; Liu, G.; Wu, L., and Wan, Z., 2016. Origins and features of oil slicks in the Bohai Sea detected from satellite SAR images. Marine Pollution Bulletin, 106(1-2), 149-154.

Ferraro, G.; Baschek, B.; de Montpellier, G.; Njoten, O.; Perkovic, M., and Vespe, M., 2010. On the SAR derived alert in the detection of oil spills according to the analysis of the EGEMP. Marine Pollution Bulletin, 60(1), 91-102.

Ferraro, G.; Trieschmann, O.; Perkovic, M., and Tarchi, D., 2012. Confidence levels in the detection of oil spills from satellite imagery: From research to the operational use. SAR Image Analysis, Modeling, and Techniques XII, 8536, 85360G.

Fingas, M.F. and Brown, C.E., 1997. Review of oil spill remote sensing. Spill Science \& Technology Bulletin, 4(4), 199-208.

Gade, M.; Alpers, W.; Hühnerfuss, H.; Wismann, V.R., and Lange, P.A., 1998. On the reduction of the radar backscatter by oceanic surface films: scatterometer measurements and their theoretical interpretation. Remote Sensing of Environment, 66(1), 52-70.

Garcia, D.A.; Bruschi, D.; Cumo, F., and Gugliermetti, F., 2013. The Oil Spill Hazard Index (OSHI) elaboration. An oil spill hazard assessment concerning Italian hydrocarbons maritime traffic. Ocean \& Coastal Management, 80, 1-11.

Ivanov, A.Y. and Zatyagalova, V.V., 2008. A GIS approach to mapping oil spills in a marine environment. International Journal of Remote Sensing, 29(21), 6297-6313.

Keydel, W. and Alpers, W., 1987. Detection of oil films by active and passive microwave sensors. Advances in Space Research, 7(11), 327-333.

Leifer, I.; Lehr, W.J.; Simecek-Beatty, D.; Bradley, E.; Clark, R.; Dennison, P.; Hu, Y.; Matheson, S.; Jones, C.E., and Holt, B., 2012. State of the art satellite and airborne marine oil spill remote sensing: Application to the BP Deepwater Horizon oil spill. Remote Sensing of Environment, 124, 
185-209.

Liu, P.; Li, X.; Qu, J.J.; Wang, W.; Zhao, C., and Pichel, W., 2011. Oil spill detection with fully polarimetric UAVSAR data. Marine Pollution Bulletin, 62(12), 2611-2618.

Liu, X.; Meng, R.; Xing, Q.; Lou, M.; Chao, H., and Bing, L., 2015. Assessing oil spill risk in the Chinese Bohai Sea: A case study for both ship and platform related oil spills. Ocean \& Coastal Management, 108, 140-146.

Lu, J.; Lim, H.; Liew, S.C.; Bao, M., and Kwoh, L.K., 1999. Ocean oil pollution mapping with ERS synthetic aperture radar imagery. IEEE International Geoscience and Remote Sensing Symposium (Hamburg, Germany), pp. 212-214.

Lu, Y.; Hu, C.; Sun, S.; Zhang, M.; Zhou, Y.; Shi, J., and Wen, Y., 2016. Overview of optical remote sensing of marine oil spills and hydrocarbon seepage. Journal of Remote Sensing, 20, 1259-1269.

Luan, X.; Zhang, F.; Guo, J.; Cui, T., and Zheng, R., 2017. Polarization characterization of laser-induced fluorescence from the simulated oil spill samples. Spectroscopy and Spectral Analysis, 37(7), 2092-2099.

Martínez, A. and Moreno, V., 1996. An oil spill monitoring system based on SAR images. Spill Science \& Technology Bulletin, 3(1-2), 65-71.

Michael John De Smith, M.F.G. and Paul, A., 2009. Geospatial Analysis : A Comprehensive Guide to Principles, Techniques and Software Tools, 3rd Edition ed. Leicester: England, 394p.

Pavlakis, P.; Sieber, A., and Alexandry, S., 1996. On the optimization of spaceborne SAR capacity in oil spill detection and the related hydrodynamic phenomena. Spill Science \& Technology Bulletin, 3(1-2), 33-40.

Pavlakis, P.; Tarchi, D., and Sieber, A.J., 2001. On the monitoring of illicit vessel discharges using spaceborne SAR remote sensing - a reconnaissance study in the
Mediterranean sea. Annales Des TelecommunicationsAnnals of Telecommunications, 56(11-12), 700-718.

Shi, L.; Ivanov, A.Y.; He, M., and Zhao, C., 2008. Oil spill mapping in the western part of the East China Sea using synthetic aperture radar imagery. International Journal of Remote Sensing, 29(21), 6315-6329.

Solberg, A.S.; Brekke, C.; Solberg, R., and Husoy, P.O., 2007. Oil spill detection in radarsat and envisat SAR images. IEEE Transactions on Geoscience \& Remote Sensing, 45(3), 746-755.

Su, W.; Su, F.; Zhou, C., and Du, Y., 2012. Optical satellite remote sensing capabilities analysis of the marine oil spill. Journal of Geo-Information Science, 14(4), 523-530.

Topouzelis, K.; Karathanassi, V.; Pavlakis, P., and Rokos, D., 2007. Detection and discrimination between oil spills and look-alike phenomena through neural networks. ISPRS Journal of Photogrammetry and Remote Sensing, 62(4), 264-270.

Xing, Q.; Lin, L.; Lou, M.; Lei, B.; Zhao, R., and Li, Z., 2015. Observation of oil spills through landsat thermal infrared imagery: A case of deepwater horizon, Aquatic Procedia, 3, 151-156.

Yu, F.; Xue, S.; Zhao, Y., and Chen, G., 2018. Risk assessment of oil spills in the Chinese Bohai Sea for prevention and readiness. Marine Pollution Bulletin, 135, 915-922.

Zhang, J.; Zhang, X.; Fan, C., and Meng, J., 2016. Discussion on application of polarimetric synthetic aperture radar in marine surveillance. Journal of Radars, 5, 596-606.

Zinck, J.A.; López, J.; Metternicht, G.I.; Shrestha, D.P., and Vázquez-Selem, L., 2001. Mapping and modelling mass movements and gullies in mountainous areas using remote sensing and GIS techniques. International Journal of Applied Earth Observation and Geoinformation, 3(1), 4353. 